\title{
PROTOCOLOS DE LEITURA: UMA EXPERIÊNCIA DE LEITURA
}

\section{COMPARTILHADA}

Luciney Rosa SUR

Programa de Pós-Graduação em Letras-Universidade do Estado de Mato Grosso

\begin{abstract}
RESUMO: Nos últimos anos vem se discutindo a questão do fracasso escolar na formação de leitores, cuja consequência é o expressivo número de analfabetos funcionais demonstrado pelos exames oficiais e, na própria escola, o acúmulo de déficits de aprendizagem pela incapacidade de grande parte dos alunos em compreender o que lê. Neste trabalho apresentase uma proposta de leitura tutorial, por meio do instrumento de protocolo de leitura proposto por Leffa (1996), bem como se tomaram por base as ideias acerca de estratégias de leitura colocadas por Solé (1998) e as contribuições de Bortoni-Ricardo e Machado (2013) quanto à leitura tutorial. Nele podemos analisar que se faz necessário um melhor embasamento teórico pelo professor, sobre o que é a leitura e os processos cognitivos, metacognitivos e sociocognitivos envolvidos, bem como um trabalho mais coeso e contínuo sobre esta entre as diversas disciplinas escolares e ainda, assumirmos que a leitura é um conteúdo procedimental que precisa ser aprendido na escola, durante todo o processo de escolarização do aluno. PALAVRAS-CHAVE: protocolo de leitura; leitura tutorial; estratégias de leitura.
\end{abstract}

ABSTRACT: In recent years has been discussing the issue of school failure in the formation of readers, whose consequence is the large number of functional illiterates shown by official inspections and, at the school, the accumulation of learning deficits for many of the students of disability. This paper presents a proposal for a tutorial reading through reading protocol instrument proposed by Leffa (1996), as were based on ideas about reading strategies posed by Solé (1998) and contributions of Bortoni-Ricardo e Machado (2013) as to reading tutorial. We can analyze that a better theoretical background is needed by the teacher about what is reading and cognitive processes, metacognitive and sociocognitive involved, as well as a more cohesive and continuous work on this between the various school subjects and yet, we assume that reading is a procedural content that needs to be learned in school throughout the student's educational process.

KEYWORDS: reading protocol; tutorial reading; reading strategies.

\section{Introdução}

Um dos papéis de maior importância atribuído à escola é o de tornar as pessoas proficientes na leitura e na escrita. Mas, é de conhecimento comum, que, no Brasil, a escola não tem cumprido esse papel, uma vez que pesquisas e avaliações ${ }^{1}$ dos sistemas de ensino têm mostrado as deficiências dos alunos nesse quesito, bem como a existência de grande quantidade de analfabetos funcionais. A leitura de textos de gêneros diversos permite o acesso

\footnotetext{
${ }^{1}$ Ver em http://www.inep.gov.br/basica/saeb/publicações.htm, também em http://www.ipm.org.br/ptbr/programas/inaf/relatoriosinafbrasil/Paginas/inaf2011_2012.aspx, acesso em 05-02-2016.
} 
a informações, ensinamentos e experiências que possibilitam a cidadania, por isso toda a ênfase dada atualmente em documentos oficiais, como os Parâmetros Curriculares Nacionais, Plano Nacional de Educação e as Orientações Curriculares da Educação Básica de Mato Grosso, na importância da formação de leitores.

Na escola, a falta de competência na leitura é fator de exclusão e deficiências no aprendizado. Muitos dos casos de déficit de aprendizagem nas várias áreas do conhecimento estão associados a isso. Porém, parece ser crença geral que o aluno deva aprender a ler somente nas aulas de Português e/ou durante a alfabetização. Há, até mesmo, falta de embasamento sobre o que seja leitura de fato, pois este conceito ainda está muito relacionado à capacidade de decifração do texto escrito, principalmente nas classes de alfabetização, onde o letramento capacidade que está relacionada aos usos efetivos da escrita e da leitura - tem estado na pauta das discussões, sem, contudo ainda ser realidade no cotidiano escolar.

Saber ler é muito mais do que decodificar, é acionar diversos conhecimentos prévios para atribuir sentido ao texto, seja verbal ou não verbal e, por isso, numa concepção ampla de leitura, ir além daquilo que se materializa diante de nossos sentidos como objeto de leitura, fazendo a mediação com a realidade vivida e podendo se posicionar de forma crítica e autônoma.

Este trabalho foi proposto pela disciplina de Aspectos Sociocognitivos e Metacognitivos da Leitura e da Escrita do Curso de Mestrado Profissional em Letras, Campus de Sinop-MT, no qual deveríamos desenvolver uma atividade prática com alunos do ensino fundamental-anos finais, com a metodologia dos protocolos de leitura, conforme Leffa (1996) e Solé (1998).

A seguir apresentamos algumas discussões teóricas sobre as concepções e estratégias de leitura e também sobre o papel do professor como mediador no processo de leitura. Depois, o relato e análise da experiência desenvolvida com protocolo de leitura e, por fim. as considerações finais acerca do trabalho.

\section{Referencial Teórico}

Houve um tempo em que se considerava que o significado do texto estava nele mesmo, ou seja, independentemente do leitor e das condições da leitura, o texto teria por si só todos os elementos capazes de garantir sua significação. Assim, o leitor experiente chegaria ao significado, que seria sempre um único.

Mais recentemente, cresceu um posicionamento contrário a essa perspectiva, em que a significação de um texto depende do leitor, sem o qual o texto não existiria, em que toda produção de significado é válida.

A visão da realidade provocada pela presença do texto depende da bagagem de experiências prévias que o leitor traz para a leitura. $\mathrm{O}$ texto não contém a realidade, reflete apenas segmentos da realidade, entremeados de inúmeras 
lacunas, que o leitor vai preenchendo com o conhecimento prévio que possui do mundo (LEFFA, 1996, p.14).

O ato da leitura passa por uma etapa fundamental que é a decodificação, mas os dados decodificados precisam ser compreendidos, quer dizer, devem criar um significado. Para isso cabe o importante papel do leitor, que nunca é passivo, pois sempre suas emoções, reações, reflexões acompanharão a busca do significado. Também não podemos considerar que o significado esteja completamente a cargo do leitor, pois a leitura requer uma parceria, para que ocorra uma interação entre este e o texto.

A compreensão de um texto está condicionada pelo contexto social e cultural do leitor. Mesmo para o texto literário, não se pode aceitar qualquer forma de compreensão, pois seu autor aponta caminhos para a leitura que vão delimitando-a. Os objetivos de leitura é que definem, não só a procura do texto a ser lido como também os procedimentos dele, além do empenho do leitor no ato de ler.

Solé (1998) defende que é preciso ampliar as propostas de trabalho com leitura na escola para todos os níveis de ensino, envolvendo todos os professores e todas as matérias, relacionando a necessidade de aprender a ler para poder aprender lendo e considerar a capacidade de compreensão e interpretação da leitura com autonomia, como forma de desenvolvimento pleno numa sociedade letrada. Para a autora, que discute leitura a partir de uma abordagem interativa, "a leitura é um processo de interação entre o leitor e o texto; neste processo tenta-se satisfazer (obter uma informação pertinente para) os objetivos que guiam sua leitura" (Solé, 1998, p. 22). Portanto, implica que haja um leitor ativo, que processa e examina o texto, e que sempre deve existir um objetivo para conduzir a leitura, o qual vai guiar a interpretação do que é lido. O leitor é quem constrói o significado do texto já que a leitura de um indivíduo pode não ser a mesma que para outro. Essa construção de sentidos depende dos conhecimentos prévios e dos objetivos de cada leitor.

Conforme os objetivos estabelecidos para cada leitura, são buscadas as estratégias que mais se adequam a eles. Os processos metacognitivos, ou seja, a consciência do que sabemos e não sabemos, do que nos falta para atingir tais objetivos, nos ajudam a construir as estratégias de leitura.

De acordo com Bortoni-Ricardo e Machado,

A compreensão textual, dentre outros fatores, é produto de estratégias que o leitor utiliza para intensificar a lembrança e a compreensão do que lê, assim como para detectar e compensar os possíveis erros ou falhas de compreensão. Essas estratégias são as responsáveis pela construção de uma interpretação para o texto, e pelo fato de o leitor ser consciente do que entende e não entende, são úteis para poder resolver o problema com o qual se depara (SOLÉ, 1998, apud BORTONI-RICARDO e MACHADO, 2013, p. 55). 
Estratégia pode ter como sinônimos: habilidade, destreza, técnica ou procedimento, que embora não sendo a mesma coisa, têm semelhanças/relações. Refere-se a um conjunto de ações ordenadas e finalizadas, ou seja, dirigidas à consecução de uma meta. Serve para regular a atividade das pessoas, porém sem prescrever totalmente o curso de uma ação. Segundo Solé (1998, p. 69), "as estratégias são suspeitas inteligentes, embora arriscadas, sobre o caminho que devemos seguir" e envolvem auto direção (existência de um objetivo) e autocontrole (supervisão e avaliação). Não podem ser tratadas como técnicas precisas, receitas infalíveis ou habilidades específicas, mas precisam ser ensinadas, pois possibilitam a formação de leitores autônomos, capazes de enfrentar de forma inteligente textos de gêneros diversos, inclusive aqueles não trabalhados na escola. Também, proporcionam que o leitor possa aprender a partir dos textos.

A autora apresenta estratégias para antes, durante e depois da leitura, mas adverte que essa divisão é um tanto artificial, pois muitas das estratégias são passíveis de trocas e estarão presentes ao longo de todo o processo de leitura. Abaixo apresentamos as principais, consoante orientações da referida autora:

- Definição dos objetivos de leitura: os objetivos de leitura determinam a forma como o leitor se situa diante dela e controla a consecução de seu objetivo, ou seja a compreensão do texto. Os objetivos são diversos, assim como o são os leitores, mas todos devem ser considerados nas situações de ensino. Há alguns objetivos que costumam aplicar-se melhor a certos textos que a outros, daí a necessidade de a escola trabalhar com a diversidade de textos que circulam socialmente. Vamos destacar alguns dos objetivos da leitura, que podem e devem ser trabalhados em sala de aula: ler para obter uma informação precisa; ler para seguir instruções; ler para obter uma informação de caráter geral; ler para aprender; ler para revisar um escrito próprio; ler por prazer; ler para comunicar um texto a um auditório; ler para praticar a leitura em voz alta; e ler para verificar o que se compreendeu.

- Atualização de conhecimentos prévios: diante do desafio da leitura, o professor deve se perguntar com que bagagem os alunos poderão abordá-la, prevendo que esta não será homogênea. Esta bagagem condiciona a interpretação que se constrói e não se refere apenas aos conceitos e sistemas conceituais dos alunos, mas também pelos seus interesses, expectativas, vivências e por todos os aspectos mais relacionados ao âmbito da afetividade e que intervêm na atribuição de sentido ao que se lê.

- Previsão: para estabelecer previsões nos baseamos nos aspectos do texto: superestrutura, títulos, ilustrações, cabeçalhos etc, os quais nos permitem antever o conteúdo do texto. Formular hipóteses, fazer previsões exige correr riscos, para tanto, é preciso ter certeza de isso é possível, ou seja, formular expectativas que, embora não sejam exatas, sejam pertinentes. $\mathrm{O}$ professor tem papel de protagonista nessa atividade, uma vez que com seus questionamentos, além de promover o compartilhamento das previsões, deve deixar claro que somente a leitura do texto poderá confirmá-las ou não. Assim indica um objetivo claro e contribui para dar significância à atividade.

- Inferência: Elaborar e provar inferências de diversos tipos, como interpretações, hipóteses e previsões e conclusões, realizando a confirmação, rejeição ou retificação das antecipações ou expectativas criadas antes da leitura; esclarecimentos de palavras desconhecidas a partir da inferência ou consulta ao dicionário; formulação de conclusões implícitas no texto, com base em outras leituras, experiências de vida, crenças, valores; formulação de hipóteses a respeito da sequência do enredo; identificação de palavras-chave; busca de informações complementares; construção do sentido global do texto; identificação das pistas que mostram a posição do autor; relação de novas informações ao conhecimento prévio; identificação de referências a outros textos.

- $\quad$ Resumo: Utilizar essa estratégia pode ser uma boa escolha para estabelecer o tema de um texto, para gerar ou identificar sua ideia principal e seus detalhes secundários. É 
importante, também, que os alunos aprendam porque precisam resumir, e como fazê-lo, assistindo resumos efetuados pelo seu professor, resumindo conjuntamente, passando a utilizar essa estratégia de forma autônoma.

Solé (1998) defende que a aprendizagem de estratégias adequadas para compreensão dos textos requer uma intervenção especialmente dirigida para esse fim. $\mathrm{O}$ aprendiz precisa do apoio, orientação, incentivo e desafios que devem ser propostos pelos professores, para ir se apropriando de aspectos da leitura, que sem isso são inacessíveis a ele. Portanto, a aprendizagem da leitura não é algo que ocorre espontânea e individualmente, nem tampouco da mesma forma para todos. Também não é algo que se restrinja a uma etapa da escolarização, mas que deve se estender por toda a escolaridade e ser vista como uma questão central no projeto curricular de todas as matérias da escola. Os recursos do ensino devem resultar em bons leitores, que sintam gosto e prazer pela leitura, já que ela deve ser encarada como principal instrumento para aprender.

Uma das formas de conceber esse processo em que o aprendiz necessita da ajuda de um par mais experiente para construir seu aprendizado pode ser explicada por meio do processo de andaimagem, que, no contexto escolar, ocorre não somente na relação professor e aluno, mas também entre os próprios alunos. Nessa concepção, a ênfase está nas relações interpessoais em que a construção do conhecimento como atributo intrapessoal, internalizado, é construída na interação entre as pessoas.

O conceito de andaime ou andaimagem (tradução de scaffolding do inglês) foi introduzido pelo psicólogo Jerome Bruner e se deriva da teoria sociocultural de Vygostsky, com base na noção de Zona de Desenvolvimento Proximal (ZDP):

\begin{abstract}
Andaime é um conceito metafórico que se refere a um auxílio visível ou audível que um membro mais experiente de uma cultura pode dar a um aprendiz. $\mathrm{O}$ trabalho de andaimagem é mais frequentemente analisado como uma estratégia instrucional no domínio da escola, mas de fato, pode ocorrer em qualquer ambiente social onde tenham lugar processos de socialização (BORTONNI-RICARDO, 2013, p. 26).
\end{abstract}

O processo de andaimagem ocorre quando o professor estabelece um processo de interação efetivo com seus alunos, dialogando com eles sobre o assunto que deseja ensinar, fazendo perguntas relevantes, ouvindo suas colocações e ratificando-as ou retificando-as. Não basta apenas dizer se a resposta do aluno está certa ou errada, mas aproveitar a oportunidade para ajudá-los a formular novas maneiras de pensar, de fazer análises e categorizar. Também, é o momento em que devem aprender a ouvir e esperar sua vez para falar, respeitando os direitos uns dos outros, desenvolvendo valores e atitudes A característica básica é estabelecimento de uma atmosfera positiva entre professor e alunos por meio de ações simples como as de se ouvirem e confirmarem ou não suas hipóteses mutuamente.

\title{
Metodologia
}

A metacognição diz respeito à capacidade do leitor de monitorar o próprio ato de leitura, em que tem consciência dos processos que utiliza para chegar ao conteúdo e a capacidade de 
avaliar a qualidade da própria compreensão. O leitor eficiente sabe também o que fazer quando está tendo problemas com o texto. Esses aspectos, mais os componentes psicogenéticos e instrucionais, irão formam o campo de estudos da metacognição na leitura. As pesquisas sobre esse tema têm contribuído para a compreensão do processo de leitura, sendo a técnica de análise de protocolos uma das mais usadas.

De acordo com Leffa (1996), o protocolo de leitura envolve basicamente uma entrevista em que o pesquisador tenta, por meio de perguntas indiretas, obter dados sobre os processos usados pelo leitor, de forma que possa descrever as estratégias de leitura utilizadas por este. "A técnica da entrevista, ao permitir que o investigador avalie a consciência que o leitor tem de suas próprias estratégias, torna também possível avaliar a correlação entre o comportamento metacognitivo do leitor e sua compreensão de leitura" (LEFFA, 1996, p. 54). Para o desenvolvimento deste trabalho foi então a técnica de pesquisa escolhida para a análise das estratégias utilizadas pelos sujeitos pesquisados.

A Escola Municipal de Educação do Campo "Antonio Pelissari" localiza-se em Vila Atlântica, um pequeno povoado, pertencente ao município de Nova Santa Helena-MT. Conta com 05 salas de aula, laboratório de informática, sala de leitura e as outras dependências necessárias para seu funcionamento. Atendeu, no ano de 2015, 60 alunos, do Pré-escolar aos anos finais do Ensino Fundamental, também atende mais 12 alunos do Ensino Médio, como extensão de uma escola estadual. Devido à quantidade reduzida de alunos, todas as turmas são multisseriadas, havendo um total de 05 turmas, sendo: Pré (I e II), $1^{\circ}$ Ciclo $\left(1^{\circ}, 2^{\circ}\right.$ e $3^{\circ}$ anos), $2^{\circ}$ Ciclo $\left(4^{\circ}, 5^{\circ}\right.$ e $6^{\circ}$ anos $), 3^{\circ}$ Ciclo $\left(7^{\circ}, 8^{\circ}\right.$ e $9^{\circ}$ anos $)$ e Ensino Médio $\left(1^{\circ}, 2^{\circ}\right.$ e $3^{\circ}$ anos $)$.

Para realização da atividade foram selecionados dois alunos do $8^{\circ}$ ano do ensino fundamental. Tais alunos foram escolhidos pelos seguintes motivos: C.A.S. é uma aluna com defasagem idade-série, muito retraída, que não desenvolve as atividades propostas em sala de aula e nunca fez uma leitura oralizada, portanto essa seria uma oportunidade de me aproximar mais dela e avaliar o seu processo de leitura. R.S.M. é um aluno bastante extrovertido e o que demonstra maior facilidade de compreensão de leitura de sua turma. De certa forma, procurei trabalhar com sujeitos cujos processos de aprendizagem pareciam-me contrastantes.

Devido à necessidade de realizar a atividade individualmente, fui à escola em um dia em que não estava em sala de aula, já que leciono a disciplina de Português para a turma. Foi preciso combinar anteriormente com a professora que estaria na classe, naquele dia, para que ela pudesse liberar os alunos para a atividade. Não foi possível realizar a atividade no contra turno porque dependia do transporte municipal para ir até a escola.

Para realização da atividade, usei a Sala de Leitura da escola, para a qual convidei os alunos, um de cada vez, explicando a eles que iriam fazer uma atividade de leitura comigo, em que iriam contribuir com curso de mestrado que faço. Eles se mostraram dispostos a colaborar e pareceram-me estar bem tranquilos com a proposta, até mesmo C.A.S. que diante da turma se mostra retraída e pouco participativa.

Organizei a atividade, com cópias de um texto cujo título é "Consumismo" o qual está num livro didático de português do $8^{\circ}$ ano, sendo um fragmento da obra "Isto É Tudo: o livro do 
conhecimento". Tal texto é do tipo argumentativo e expõe a opinião do autor sobre as estratégias usadas por supermercados e shoppings centers para atrair os consumidores e aumentar suas vendas. Preparei também um esquema, com algumas partes preenchidas e outras para que o aluno preenchesse, com as ideias principais do texto. Essa atividade seria feita posteriormente à leitura compartilhada, assim como a produção de um resumo.

O tema "consumo" já vinha sendo trabalhado a partir de uma unidade do livro didático de português adotado na turma, na qual já desenvolvêramos atividades como leitura de charges, anúncios publicitários e propagandas, estudo do imperativo na linguagem persuasiva e também produção de textos do gênero anúncio publicitário.

\section{Relato e análise do procedimento}

Devido ao limite de páginas que devem compor este texto, não apresentarei as entrevistas na íntegra. Selecionei alguns trechos que me pareceram significativos para ilustrar o uso de estratégias de leitura, bem como a função da leitura compartilhada ou tutorial.

Entende-se como leitura tutorial aquela em que o professor exerce papel de mediador durante o processo de leitura e compreensão; nessa proposta, o professor deve atuar fazendo intervenções didáticas, por meio das quais interage com os alunos, a fim de conduzi-los à compreensão do texto. A leitura tutorial é pois uma leitura compartilhada (BORTONI-RICARDO, 2013, p. 51).

Com base nesses preceitos é que fui conduzindo o processo, buscando intervir fazendo perguntas relevantes, para auxiliar os alunos a fazerem uma leitura significativa.

\section{Protocolo realizado com o aluno R.S.M}

Antes da leitura: Estávamos sentados diante um do outro, na Sala de Leitura. Entreguei-lhe uma cópia do texto, após já ter explicado o motivo da atividade, e fui questionando sobre os elementos como o título, ilustrações, glossário, etc. para verificar as previsões que faria.

Prof :: O título do texto "Consumismo" te lembra o quê?

R.S.M.: Consumir?

Prof ${ }^{\mathrm{a}}$. Consumir bastante, pouco... Como assim?

R.S.M.: Comigo é bastante...

Prof $^{\mathrm{a}} .:($...) Bom, aqui do lado do texto tem algumas palavras e tal, para que serve isso daqui?

R.S.M.: Pra gente saber as palavras que não entende.

Prof $^{a} .:$ Hahã, isso, saber o significado de algumas palavras, né, aquelas que talvez seja um pouco mais difícil de

saber o significado, é isso?

R.S.M.: É...

Prof $^{\mathrm{a}}$ : Aqui a gente tem uma figura, o que você vê nessa figura aqui?

R.S.M.: As pessoas e uma mulher comprando. Aqui é as pessoas acho que economizando e a mulher

comprando...

Prof $^{\mathrm{a}} .:$ Economizando?

R.S.M.: Fazendo a prancheta. 
Prof $^{\mathrm{a}} .:$ Ah, usando uma prancheta... Pra que que elas estariam usando essa prancheta?

R.S.M.: Pra somar os lucros?

Prof $^{\mathrm{a}}$.: Hahã... E esses cartazes aqui, o que são?

R.S.M.: De um produto novo e a promoção de produtos.

Prof ${ }^{a}$.: Hahã. E esses homens aqui de óculos, mulher de óculos, assim, eles têm cara de quê?

R.S.M.: O dono do mercado.

Prof ${ }^{\mathrm{a}}:$ O dono do mercado? Hum... e eles estariam olhando essa mulher aqui pra quê?

R.S.M.: Pra ver o que ela compra.

Figura 1 - Trecho de protocolo de leitura realizado com o aluno R.S.M.

Nesse fragmento foi possível perceber que, embora o aluno tenha se equivocado nas suas previsões relativas às imagens presentes no texto, elas não deixaram de ser pertinentes. Tais imagens referiam-se aos supermercados-laboratórios e os homens e mulheres de óculos, com jalecos e pranchetas, seriam os cientistas e especialistas fazendo observação do comportamento do consumidor nesse ambiente. A imagem faz referência a essa informação que está presente no texto escrito. $\mathrm{O}$ aluno, a princípio pensa que possivelmente a prancheta está servindo para pesquisa de preços pelo consumidor, já que responde "Economizando?", mas depois corrige sua previsão, pois demonstra ter passado a pensar que possivelmente seriam os donos do supermercado, os quais estariam somando os lucros.

Um equívoco cometido por mim, não foi ter esclarecido ao aluno que suas previsões seriam confirmadas ou não depois pela leitura, que não tinham que estar certas, mas que eram apenas previsões. Isso talvez teria lhe deixado mais seguro, já que em algumas de suas respostas eram perguntas, nas quais ele demonstrava insegurança e solicitava uma confirmação. Também deveria ter estabelecido um objetivo para a leitura, o que poderia instaurar um elo entre o texto e os alunos, conforme diz Solé (1998).

Depois, foi dado um tempo para que o aluno fizesse uma leitura silenciosa para que tivesse um contato inicial com o texto, conforme sugerem Bortoni-Ricardo e Machado (2013). Terminada essa leitura, esclareci que iríamos fazer uma leitura compartilhada, ou seja, pedi que o aluno fizesse a leitura em voz alta e eu iria fazer intervenções para ajudá-lo a compreender melhor o texto. As mesmas autoras ressaltam que nessa leitura simultânea entre professor e alunos, todas as dimensões do texto precisam ser compreendidas, na qual o professor deverá explorar o texto do ponto de vista semântico e pragmático e os alunos serão conduzidos ao desenvolvimento de estratégias que propiciarão a compreensão do texto.

Prof $^{\mathrm{a}}$.: Vamos ler o primeiro parágrafo aqui. Você pode ler pra mim, em voz alta?

R.S.M.: "Tudo parece ser mágico, grande e alegremente ana... anárquico. Há música em todos os locais..."

Prof.$:$ Só um pouquinho...O que significa "anárquico", você sabe?

R.S.M.: "Confuso, de... desordenado". (Ele lê no glossário)

Prof ${ }^{a}$ : Isso, então está dizendo ali "Tudo parece ser mágico, grande e alegremente..."

R.S.M.: Anárquico...

Prof $^{a}$.: Anárquico, né, parece uma confusão alegre, né, como uma festa, uma confusão alegre, né? (Continua a leitura) "Há música em todos os locais, as vitrines..."

R.S.M.: “...estão muito bem des... decoradas. O ambiente está propício para um passeio gratificante.”

Prof $^{\mathrm{a}}$.: Hahã. "O ambiente está propício...” O que significa propício?

R.S.M.: Adequado?

Prof ${ }^{a}$.: Isso, adequado, né, está, está bom para se fazer um passeio gratificante. 
Neste trecho, ocorreram dois exemplos em que houve esclarecimentos de palavras desconhecidas. No caso da palavra "anárquico" o aluno se valeu do glossário presente no texto, já com a palavra "propício" foi a partir de inferência, pois a mesma não constava no glossário.

Profa $^{\mathrm{a}} .:$ Continua...

R.S.M.: "Estamos, quase sem perceber, em uma selva de consumo onde inevitavelmente cairemos em algumas das 'armadilhas' que equipes formadas por psicólo...psicosso...sociologos...

Prof ${ }^{a}$ : Psicossociólogos. Pode repetir?

R.S.M.: Psicossociólogos.

Profa.$:$ Isso...

R.S.M.: “...arquitetos, decoradores, iluminadores e especialistas em marketing preparam para os consumidores potenciais".

Prof ${ }^{a}$. Isso. Quando diz ali "Estamos, quase sem perceber em uma selva de consumo", o que que é selva?

R.S.M.: Selva é um lugar que tem árvores, bichos...

Prof ${ }^{\mathrm{a}}$ : Isso. E porque diz que estamos numa selva de consumo, o que selva tem a ver com consumo?

R.S.M.: Lugar tá muito... Porque é grande, tem bastantes produtos...

Prof ${ }^{\mathrm{a}}:$ : Assim como numa selva tem bastante árvores?

R.S.M.: Hahã.

Figura 3 - Trecho de protocolo de leitura realizado com o aluno R.S.M.

Neste trecho verifica-se que o aluno realizou uma inferência em relação à metáfora "selva de consumo", associando "selva" ao ambiente espaçoso e repleto de produtos que são os supermercados.

Prof $^{\mathrm{a}}$ : Por que a palavra marketing tá com a letrinha diferente? (Pausa) Aqui embaixo a palavra shopping center tá com a letrinha diferente, porque será?

R.S.M.: Tá escrito em inglês?

Prof ${ }^{a} .:$ Hum...essas palavras são em inglês, né, e a letra é diferente por quê?

R.S.M.: Porque tá tentando colocar em brasileiro.

Prof ${ }^{a}$ : Tão tentando colocar em brasileiro?

R.S.M.: É.

Prof ${ }^{a} .:$ Hum... É porque elas são palavras estrangeiras, aí quando aparece uma palavra estrangeira, num texto, no caso em português, ela vem destacada, né, então você pode ver que a letra tá um pouquinho mais deitadinha do que as outras, né. Isso é pra destacar a palavra pra mostrar pro leitor que essa palavra não é da nossa língua, é uma palavra de uma língua estrangeira.

Figura 4 - Trecho de protocolo de leitura realizado com o aluno R.S.M.

Aqui se procurou chamar a atenção do aluno para uma questão de ordem estrutural do texto, que apresenta a palavra "marketing" e "shopping center" em itálico, visando investigar se ele saberia o motivo. Vemos que ele responde corretamente sobre o motivo, porém acredita que a letra é diferente por que estariam tentando "aportuguesar" as palavras.

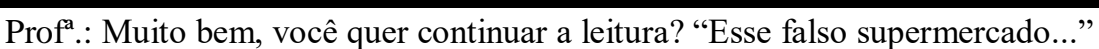

R.S.M.: "Esse falso supermercado onde as cobaias são os clientes, é o menor do mundo - possui apenas duzentos metros quadrados, com música ambiente. Os visitantes são selecionados em supermercados verdadeiros e recebem, ao entrar, uma lista de compras."

Prof $^{\text {a }}$.: Tá, só um pouquinho. Então esse supermercado, diz aqui que é o menor do mundo, né, possui apenas duzentos metros quadrados. Duzentos metros é muito, ou é pouco, que tamanho que você imagina que seja duzentos metros quadrados?

R.S.M.: Quadrado é pouco.

Prof ${ }^{\mathrm{a}}$ : : Pouco?

R.S.M.: Cinquenta metros cada lado 
Prof $^{\mathrm{a}}$. : Hum, cinco vezes cinco, vinte e cinco, daria duzentos e cinquenta, né. É até menor do que isso, né. Seria mais ou menos o tamanho de um terreno de dez metros por vinte, né, o tamanho de um terreno na cidade, assim, mais ou menos como o Mercadinho Três Irmãos lá de Santa Helena, conhece?

R.S.M.: Conheço.

Prof $^{\mathrm{a}}$ : Então, aqui diz que é o menor do mundo porque está se falando de supermercados, né, que são bem maiores. Por exemplo, que supermercados você conhece?

R.S.M.: O Machado, o Atacadão de Sinop e o Machado de Matupá.

Prof $^{\mathrm{a}}$ : Esse são super, né?

R.S.M.: Sim.

Prof ${ }^{\mathrm{a}}$. Isso...

Figura 5 - Trecho de protocolo de leitura realizado com o aluno R.S.M.

Neste trecho da entrevista destaca-se a necessidade de articulação das informações com conhecimentos prévios e conhecimentos extratextuais, como no caso da ideia de tamanho pela medida de duzentos metros quadrados, que o aluno respondeu adequadamente embora fizesse o cálculo equivocada (50x4). Procurei explorar seus conhecimentos de mundo, fazendo-o relacionar ao tamanho de um estabelecimento de sua cidade. Também o fiz, quando perguntei que supermercados o aluno conhece.

\section{Protocolo com a aluna C.A.S.}

Da mesma forma que fiz com o aluno R.S.M., entreguei a cópia do texto à aluna e comecei a exploração dos elementos antecedentes à leitura do texto, como o título, o glossário e as ilustrações. Na preparação para a leitura do texto, segundo Bortoni-Ricardo e Machado (2013), é preciso estabelecer com que finalidade o texto deverá ser lido, uma vez que a leitura é realizada de acordo com o objetivo que se tem diante de um texto. Então, expliquei para a aluna que leríamos aquele texto para ampliar os conhecimentos sobre o tema do consumo, sobre o qual já havíamos estudado. Também essas autoras acrescentam outra atividade relevante antes de iniciar a leitura que é a realização de previsões sobre o texto, na qual podemos recorrer a vários aspectos como o formato do texto, estrutura textual, ilustrações, títulos, subtítulos que, de acordo com nossos conhecimentos prévios e nossa experiência nos permitirão antever o assunto sobre o qual tratará o texto.

Prof ${ }^{a}$ :Nós vamos ler um texto expositivo cujo título é "Consumismo". "Consumismo", sobre o que você acha que esse texto vai falar com esse título?

C.A.S.: Consumo das pessoas?

Prof $^{a}$ ::Hahã. É, dá uma observada aí na folha, aqui ao lado tem algumas palavras, pra queserve isso aqui? Umas palavras com seus respectivos significados

C.A.S.: Anarquismo é o confuso, desordenado...

Prof ${ }^{a}$ : Certo, aí você tá lendo a palavra e significado, mas pra que serve isso aqui ao lado do texto?

C.A.S.: Pra pessoa conseguir entender as palavras que tão no texto...

Prof $^{a}$.: Hahã... Na segunda folha a gente tem uma ilustração. O que você vê nessa ilustração? Como que você interpretaria esse desenho?

C.A.S.: É a mulher gastando dinheiro com... Ah, é uma mulher gastando dinheiro. Ela tá indo pra uma promoção, em que ela vai consumir.

Prof $^{a} .:$ E esses homens ali atrás, homem, mulher de óculos com pranchetas, o que eles estariam fazendo, quem seriam eles?

C.A.S.: Eles tariam analisando ela?

Prof $^{a}$.: Hahã. Isso que você fez agora são previsões. Nós vamos confirmá-las ou não durante a leitura do texto. 
Neste momento, embora com alguma confusão a princípio, devida talvez ao nervosismo por estar sozinha com a professora, a aluna responde corretamente a todos os questionamentos, inclusive em relação às ilustrações; ela percebe que os personagens de óculos com pranchetas estariam analisando ou observando a mulher que faz compras. No caso deste protocolo, eu não me esqueci de observar em voz alta que se tratava de previsões, que poderiam ser confirmadas ou não durante a leitura. De acordo com Bortoni-Ricardo e Machado (2013), é também importante instigar o leitor a assumir reponsabilidades perante a leitura; por isso, o aluno/leitor não deverá apenas responder ao que lhe é questionado, mas deve também interrogar-se sobre o texto.

Prof $^{a} .:$ Você pode iniciar a leitura em voz alta?

C.A.S.: "Tudo parece mágico, grande e alegremente anarqui...anar...qui..anárquico. Há música em todos os locais. As vitrines estão muito bem decoradas. O ambiente está propício para um passeio gratificante. Estamos, quase sem perceber, em uma selva de consumo onde, inevitavelmente, cairemos em algumas das 'armadilhas' que equipes formadas por psicossociólogos, arquitetos, decoradores, iluminadores e especialistas em marketing preparam para os consumidores potenciais.

Prof :: Ok, no primeiro período do texto a gente tem aí a palavra "anárquico". O que significa essa palavra?

C.A.S.: "Confuso e desordenado" (Lê o glossário). Uma pessoa confusa ou desordenada.

Prof ${ }^{a}:$ E na frase ali, quando diz "tudo parece mágico, grande e alegremente anárquico"?

C.A.S.: É que a pessoa, ela tá vendo tudo de uma forma que está atraindo ela a consumir o produto, que está atraindo ela a ir comprar na loja...

Prof .: Hahã. Diz ali, é... o texto começa, né, dizendo que que "tudo parece mágico, grande e alegremente anárquico"? Você viu ali no glossário que anárquico significa "confuso, desordenado" e "alegremente anárquico"?

C.A.S.: É... uma coisa alegremente confusa, é... uma coisa que te confunde

Prof $^{\mathrm{a}}$.: Isso, mas é alegre, né?

C.A.S.: É

Figura 7 - Trecho de protocolo de leitura realizado com a aluna C.A.S

Aqui se inicia a leitura do texto, ou seja, o segundo momento "durante a leitura". A aluna atribui o significado de anárquico como se o adjetivo estivesse relacionado a uma pessoa e não ao ambiente de um determinado local. Eu, como professora, não soube intervir adequadamente para que ela compreendesse que se referia ao ambiente, porém com a releitura feita por mim do trecho do texto e do significado da palavra anárquico, ela inferiu que não se tratava de uma pessoa a que o adjetivo anárquico se referia, já que passou a dizer que se tratava de uma "coisa". É interessante observar que é recorrente o fato de que quando o professor lê, a aluna compreende. Talvez por sua leitura ainda estar muito voltada para a decodificação correta, que não a deixa prestar maior atenção ao sentido do que lê.

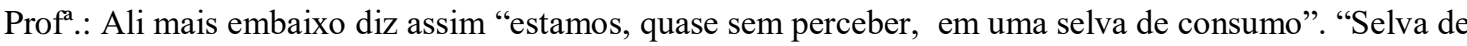
consumo", como que você interpreta essa expressão?

C.A.S.: Que é um lugar onde a pessoa vai consumir muito...Tem muita coisa pra ela consumir..

Prof".: E "selva", que ideia você associa, porque usou-se aqui a palavra selva? O que é selva?

C.A.S.: Ah, selva é um lugar...é um lugar... ah, onde tem muita coisa, um lugar isolado mas tem muita coisa...

Prof ${ }^{a}$.: Selva, né, é...seria um ambiente, relativo ao ambiente selvagem, floresta...

C.A.S.: É...

Prof ${ }^{\mathrm{a}}$ : Rios, né, bichos... então, quando fala em "selva de consumo" aqui tá se referindo à... à questão de que vivemos como numa selva, ou seja, na selva os animais têm que se comer uns aos outros pra poder sobreviver, né, é uma luta constante, eles têm, muitas vezes, que ... que... que.., se... é... é... se debater, um atacar o outro e tal, pra conseguir a sua sobrevivência. Quando diz aqui, "selva de consumo" está se associando mais ou menos essa ideia de selva aí, onde um quer ser maior de que o outro, um quer se se sobrepor ao outro pra consumir. Diz ali também "onde inevitavelmente cairemos numa das armadilhas" O que significa a palavra "inevitavelmente"? C.A.S.: Que...é uma coisa que...inevitável... que você não vai conseguir se... segurar, não consumir alguma coisa, você vai ter que vai... você vai ter que cair de algum jeito na armadilha. 
Em relação à expressão "selva de consumo", vemos que a aluna faz inferências plausíveis, embora não consiga ampliar sua argumentação, o que é feito pela professora. Quanto ao significado de "inevitavelmente", ela responde corretamente e aplicando ao contexto onde a palavra aparece. Conforme é possível observar, para que haja compreensão, é preciso diversas habilidades por parte do leitor. De acordo com Palácios (2003), apud Bortoni-Ricardo e Machado (2013), essas habilidades são decodificação, reconhecimento do vocabulário, utilização de conhecimentos prévios, capacidade de usar o texto para gerar novas aprendizagens.

Profa.$:$ Certo. É... Diz ali "equipes formadas por psicossociólogos, arquitetos, decoradores,

iluminadores e especialistas em marketing preparam para os consumidores potenciais". É... A palavra marketing está com a letra diferente, né, você percebeu? Porque que a letra da palavra marketing é diferente, as letras que compõem a palavra marketing elas...elas são mais deitadinhas e tal?

C.A.S.: Porque tá querendo dá uma diferença, alguma coisa assim pra pessoa...?

Prof ${ }^{a} .:$ Sim. Exatamente. Está querendo é ... destacar a palavra, né, mas destacar porquê?

C.A.S.: Ah...

Profa ${ }^{a}:$ Vamos repetir... Bom, a palavra marketing e a palavra shopping center têm a letra diferente, por quê?

C.A.S.: Porque não é uma palavra que a gente usa sempre no nosso dia a dia, que é uma palavra da língua inglesa, então aí fica mais destacado pra gente... ah, pra gente... chamar mais atenção da gente, pra gente ler...

Prof $^{\mathrm{a}}$ : Ok. Muito bem.

Figura 9 - Trecho de protocolo de leitura realizado com a aluna C.A.S

Novamente, com alguma dificuldade de argumentação à princípio, mas depois, com o esclarecimento da professora, a aluna consegue responder de forma acertada o motivo pelo qual as palavras de língua estrangeira estão em destaque.

Prof $^{\mathrm{a}}$.: Bom, seguindo aí a leitura, pode continuar...

C.A.S.: Pois... "Na França, por exemplo, funciona desde 1989, um supermercado laboratório onde o comportamento do consumidor é observado e analisado em detalhes. Esse falso supermercado onde a... onde as cobaias são os clientes, é o menor do mundo - possui apenas duzentos metros quadrados, com música... com música ambiente. Os visi..."

Prof ${ }^{\mathrm{a}}$ :Isso. Duzentos metros quadrados é muito ou é pouco...?

C.A.S.: É pouco...

Prof $^{\mathrm{a}}$.: Que tamanho seria duzentos metros?

C.A.S.: É pouco,

Prof $^{a}$.: Hahã..

C.A.S.: Bem pouco...

Prof $^{\mathrm{a}}$.: Você associaria duzentos metros quadrados com o tamanho de quê, por exemplo?

C.A.S.: De uma farmácia, de uma dessas lojinhas de boutique?

Prof $^{a}$.: É, um pouquinho maior, né, se a gente pensar duzentos metros quadrados seria uma construção de mais ou menos de dez por vinte metros, o tamanho, quase, de uma data, né, de um terreno na cidade. A gente poderia dizer, por exemplo, é... seria parecido ali, com o tamanho do Mercadinho Três Irmãos...

C.A.S.: É...

Prof ${ }^{a}$.: Por isso seria pequeno, né. Porque aqui a gente está falando de supermercados. Você conhece algum supermercado?

C.A.S.: Conheço.

Prof $^{\mathrm{a}}$ :: Quais, por exemplo?

C.A.S.: O Atacadão..., o Machado, Aurora...

Prof $^{\mathrm{a}}$.: Isso. Esses são supermercados, né, porque eles é... têm um tamanho bastante grande, têm uma variedade de produtos, alguns inclusive vendem eletrodomésticos, roupas e tudo mais. 
Neste trecho é possível perceber que a aluna tem dificuldade em estimar quanto seriam duzentos metros quadrados, dizendo que seria "bem pouco", do tamanho de uma farmácia ou uma lojinha. Novamente aqui procurei fazer com que ela conseguisse ter uma dedução mais aproximada do tamanho real. Depois, procuro fazer com que a aluna compare ao tamanho de supermercados reais, os quais ela conheceria. Para atingir a compreensão do que lê, o leitor depende de seu conhecimento de mundo, de relacionar o que traz de conhecimento prévio com a informação textual.

Bortoni-Ricardo e Machado (2013) discutem que no momento da leitura deve haver uma preocupação com o desenvolvimento de uma compreensão daquilo que está explícito e também daquilo que está implícito no texto. Na leitura literal devem-se recuperar as informações fornecidas pelo texto e analisá-las, deter-se no vocabulário, nas expressões metafóricas e nos termos técnicos. Para ir além da compreensão literal, há necessidade de deduzir o que está implícito, para que se atinja a compreensão inferencial. Para isso é preciso que o professor atue como mediador, desenvolvendo estratégias para que as lacunas do texto sejam preenchidas.

Depois da entrevista foi apresentado um esquema que reunia as ideias principais do texto, sendo que o mesmo estava parcialmente preenchido e deveria ser completado pelos alunos.

Segundo Rupay (2008) apud Bortoni-Ricardo e Machado (2013), uma estratégia para verificar a compreensão do texto após sua leitura é sugerir a elaboração de organizadores gráficos (mapas, redes, diagramas, quadros, mapas conceituais), o que consiste em mostrar a informação obtida por meio da leitura de um texto visualmente. Esses revelam a maneira de compreender o texto e é uma estratégia que atende a textos contínuos, ou seja, textos compostos por sentenças que são organizadas em parágrafos. $\mathrm{O}$ autor sugere que, caso o texto não seja contínuo (um gráfico, por exemplo), então seja feito o contrário, ou seja, propor que o conteúdo seja apresentado por meio de um texto contínuo.

No esquema, reproduzido parcialmente abaixo, vê-se que os alunos demonstram ter conseguido extrair as informações corretas para completar o esquema, eliminando redundâncias e ideias secundárias. Abaixo está reproduzido parte do esquema completado pelo aluno R.S.M.

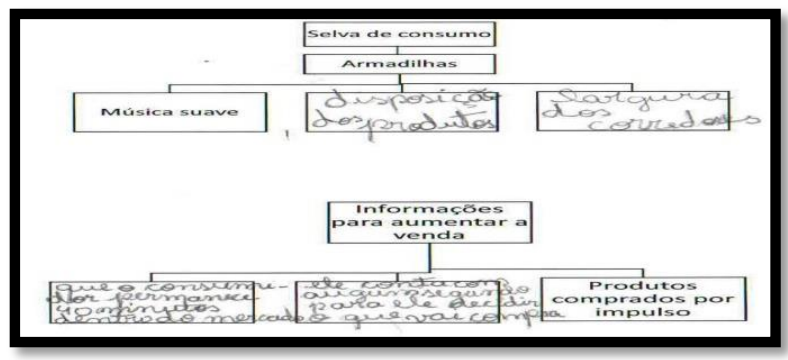

Figura 11: Esquema a partir do texto "Consumismo" (BORGATTO et. al., 2012, p.103).

Esquema da aluna C.A.S.: 


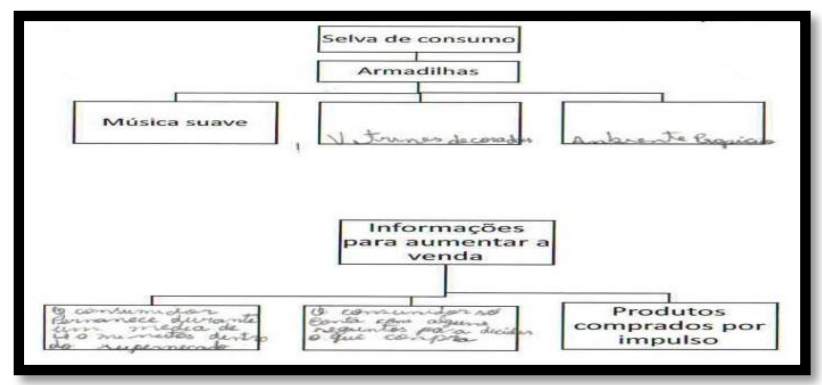

Figura 12: Esquema a partir do texto "Consumismo" (BORGATTO et. al., 2012, p.103)

Após a atividade com o esquema então, foi proposto um resumo. Disse a eles que, para fazer o resumo poderiam se basear no esquema, completando-o com palavras próprias.

Bortoni-Ricardo e Machado (2013) sugerem o resumo como uma das atividades após a leitura, que pode ser realizada para avaliá-la. Para as autoras sua importância reside no fato de que possibilita ao leitor apresentar as ideias principais do texto, o que só será possível se ele houver compreendido o que foi lido. Vejamos um trecho do resumo do aluno R.S.M.:

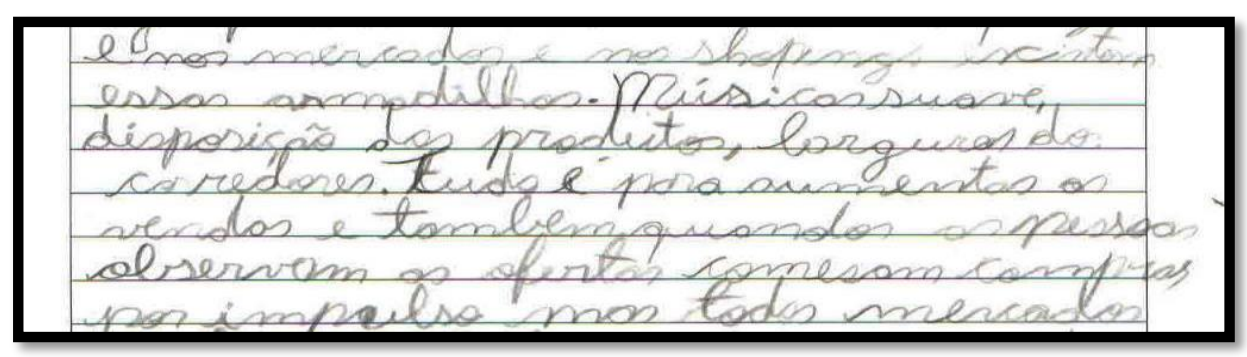

Figura 13 - Trecho de resumo realizado com o aluno R.S.M.

Agora um trecho do resumo de C.A.S.:

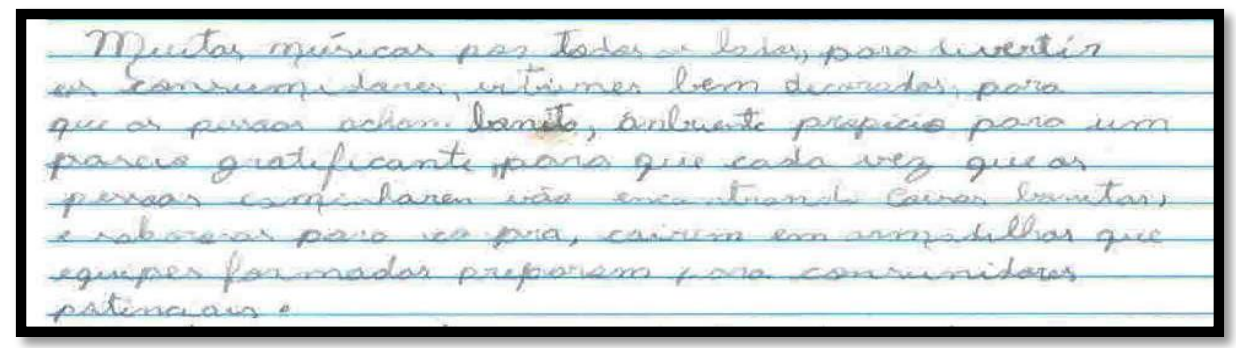

Figura 14 - Trecho de resumo realizado com a aluna C.A.S

Os trechos acima, embora tenham problemas de paragrafação, ortografia, pontuação, repetições e outros, revelam que os alunos compreenderam o que foi lido e também a capacidade de síntese das ideias do $2^{\circ}$ parágrafo, procurando reproduzir, à sua maneira, no resumo proposto. O resumo também serve para indicar ao professor as dificuldades que o aluno tem na sua produção de texto, o que pode ser trabalhado em seguida por meio de tarefas de refacção. 


\section{Considerações finais}

Neste trabalho consideramos as discussões sobre os processos cognitivos e metacognitivos envolvidos no processo de leitura, nas quais vimos que ler é um processo de representação em que olhamos para algo e vemos outra coisa. Então a forma como, na maioria das vezes, a escola tem trabalhado com a leitura, não indo além da mera decodificação, é o que pode explicar os baixos níveis de compreensão leitora apresentados pelos nossos alunos. É preciso que a escola se desburocratize e assuma sua tarefa de desenvolver atividades que propiciem o desenvolvimento de habilidades leitoras ao longo da educação básica para todos os alunos.

Aplicamos o instrumento protocolo de leitura como uma forma de leitura compartilhada, em que o professor auxilia o aluno a desenvolver estratégias de compreensão leitora, o que lhe permitirá detectar os erros e falhas de compreensão e construir uma interpretação para o texto, estando consciente do que entende e não entende. Vimos que a metacognição na leitura trata do problema do monitoramento da compreensão feito pelo próprio leitor durante o ato da leitura e envolve a habilidade para monitorar a própria compreensão e para tomar as medidas adequadas quando a compreensão falha.

Diante disso cabe questionar se, da forma como vem se desenvolvendo o trabalho cotidiano nas salas de aula, tem sido possível que os alunos considerem os processos cognitivos metacognitivos durante a aprendizagem, pois a extrema artificialização e burocratização do processo ensino e aprendizagem têm levado a um processo de escamoteamento da realidade, em que os alunos não têm consciência de que precisam aprender para se tornarem seres humanos melhores, mas sim apenas "ficar na sala de aula" para receberem seus certificados de escolarização.

Por isso, a forma como foi realizado este trabalho se mostrou válida mas limitada, uma vez que os alunos se mostraram responsáveis, participativos, mais autônomos, concentrados e dispostos a aprender, porém esta condição de estarem presentes apenas o professor e um aluno foge à realidade cotidiana. $\mathrm{O}$ ambiente coletivo da sala de aula em escolas públicas, na maioria das vezes, não propicia condições de diálogo entre professor e alunos, devido aos problemas de indisciplina, já que a maior parte dos alunos, pegando o viés da burocratização escolar, acredita que somente são válidas as atividades "no caderno", pois estas ficam registradas. Também, nos anos finais do Ensino Fundamental, temos a separação das aulas em disciplinas, o que muitas vezes reduz os momentos com os alunos a, no máximo, quatro horas semanais, o que se torna pouco para um trabalho significativo no momento em que os alunos estão aprendendo a melhorar as capacidades cognitivas por meio das capacidades metacognitivas.

Um dos desafios que fica para nós professores é de superar esse estado de coisas e desenvolver em nossos alunos a capacidade de pensar, refletir, argumentar, dialogar também sobre o "como se aprende" os conteúdos escolares, cujo papel da escola é ensinar. É preciso criar momentos de atendimento mais individualizado ou em grupos menores para conseguirmos investigar melhor os processos cognitivos e metacognitivos de nossos alunos e com isso ajudá-los a perceber que o sentimento do saber é a principal conquista do aluno na escola. 


\section{Referências}

BORGATTO, Ana Maria T. et. al. . Projeto Teláris: Português. $1^{\mathrm{a}}$ ed. Vol.3. São Paulo: Ática, 2012

BORTONNI-RICARDO, Stella M. et. al. Formação do professor como agente letrador. São Paulo: Contexto, 2013.

LEFFA, V. J. Aspectos da leitura: uma perspectiva psicolinguística. Porto Alegre: SagraLuzzatto, 1996.

SOLÉ, I. Estratégias de leitura. Tradução de Cláudia Schilling. 6. ed. Porto Alegre: ArtMed, 1998. 
